\title{
Aesthetics of camera movement in Afghan cinema
}

\author{
Abbas mohammadi \\ Afghan film, Afghanistan
}

\begin{abstract}
The movement of the camera in the cinema alone cannot create a beautiful image because it is just a movement. But when the camera movement is mixed with mezzanine and composition it can create a feeling and convey it to the audience In essence, it evokes the audience's inner feelings about the subject and the story being told within the film. Each film has a specific narrative for its story. Special narration of the film story, the specific type of movement requires the same story Therefore, great care must be taken in the type of use of camera movements because if the type of camera movement does not match the type of drama narration and film structure In terms of effectiveness, it can damage the film And it has the opposite effect and as a result causes the film to fail for a specific and general audience.

In the past, most movements were performed with the simplest tools in many cases, these movements could not properly convey that sense of movement to the audience. But today the movements are done with advanced and precise tools. In Western countries, the moving objects in the cinema are mostly controlled by very precise computer tools and exactly the movement that the director intends to achieve. But in a country like Afghanistan, which is far behind Western countries in terms of technology and modernity, they still use the same old tools. This makes camera movements very basic in films made in Afghanistan. Of course, it should not be forgotten that given the economic situation in Afghanistan, Filmmakers cannot provide the minimum tools they need. They try to make many tools by hand from the least available tools to produce their favorite movie.
\end{abstract}

Keywords: Aesthetics, Cinema, Camera Motion, Technology, Composition

\section{Introduction}

With the invention of cinema by the Lumière brothers and its evolution, cinema has faced many ups and downs. This article does not cover all of them. With the advancement of technology and the passage of time, this visual media slowly, slowly to attract more audience, added to its charms every day and increased its fans. In each semantic and technical part that the cinema developed, it added to its differences and in return, it added to the cinema audience. Changes took place in the opposite sections. One of these sections, which can be said to have created a revolution in cinema, was editing. With the advent of assembly, new ideas and techniques by thinkers such as Eisenstein, Kolschoff, Pedoffkin, and Griffith added to the magic. Entering the mezzanine of the scene, arranging the light on the stage, sound composition, creating music, using new acting methods and normal and combined camera movements in the scene and the use of close-up shots, in addition to the innovation of this dynamic visual art, each of these sections alone had a special aesthetic for itself. And they were able to add to the appeal of the cinema image and multiply the impact of cinema and cinema image. So that the filmmaker can convey his message to his specific and general audience in the best possible way.

Part of this change came in the technical means and tools of cinema production. These tools were created in different parts of cinema production. Some of these tools can be said to be movement tools such as trawling and crane. The tools that made the camera move. A movement that created a special attraction for the cinema audience. In general, camera movements in cinema are divided into movements using tools without tools. These movements cannot be considered separate or superior to each other because each of them has a special meaning and concept and creates a special feeling in the audience. But it should not be forgotten that the movements of the camera with the tool have a stronger feeling than the movements of the camera without the use of the tool. And its impact on the audience is very high.

\section{Move}

Motion basically means displacement that is used against static. Another meaning of movement can be translated into vivacity, which can again be used against being still. The movement is always dynamic and gives a sense of dynamism to the other side and transmits the movement. And it creates a sense of movement in the viewer. Motion is the essence of cinema. The image of cinema finds meaning with movement. And it moves time in itself because if we take the movement from the cinematic image, it becomes the same image that loses its meaning of being a film and a moving image.

Let's not forget this cinema is a move Pictures and mistake on human vision system Understand the gap between registered images at the speed of 24 frames per second to see him put on display, is built. The film is actually an illusion of motion frames to make the viewer moves. In essence, the audience of this seemingly false move and the illusion that has arisen for him creates a semantic space for itself and he enjoys seeing it, even if it's a lie and does not have material existence and natural science.

It can never move at any time and place Do it for no reason and on its own All movements, whether in nature or in cinema, must have a motive and a reason. Directors, camera unnecessarily and without having an ideology and a specific goal in mind, to move not. The number of directors to attract your audience and to showcase their technical abilities Moves strange and 
dizziness cinema camera in use there is no purpose behind them and they do not convey no idea. Today Hollywood Cinema and American films Full of dizzying camera movements whose only aim is fascinated by the spectators in the theater. A movie director who wants to produce Have different effects in cinema detect camera movement to help them advance their ideological purpose to use in the film. Some of these is dynamic effects and some of them are Aesthetics if the director wants properly convey the feeling of the scene to the audience by moving the camera it must separate the two and use each of them in its place.

Use camera movements in principle to guide the audience's eyes and create a special feeling within him and the induction of a logical point or dramatic effect in the direction of the drama and story of the film Of course, we should not forget that a dramatic scene It cannot be formed by binoculars alone But other factors such as framing and lighting and stage design and other things are also involved. Because the same application that is expected from lighting and framing should not be considered independently of the art of filming. It should be a combination of framing, lighting, using a lens with the desired depth of field and camera movement this point should not be forgotten the dramatic load of the image is based on the use of light shadows, depth of field, and the size of the view and the movement of the camera. All camera movements vary depending on the type of framing, the movement of the actors, the inner sense and action of the scene, and the overall rhythm of the film's storytelling. Not using the camera properly does not hide from the curious gaze of the audience. Every movement of the camera provides the viewer with information about space and location and an illusion creates a three-dimensional space of two-dimensional image for the audience which directly affects the audience's mental image.

The movement of the camera can convey a strange feeling to the audience. Like the strange and brilliant combination of the camera in the stairwell of Alfred Hitchcock's "Dizziness" that gives a sense of perspective. And it evokes a kind of dizziness of the main character and fear of heights. Another example of the camera's short, long, low-height steady motion can be seen in "Birdman." In this film, long scenes are taken by Steady and makes the audience follow the character of the film by moving the camera and accompany him throughout the scene. The camera can move closer to the actor and the scene and pay more attention to the details or move away from them and show the relationship between the components and the scene. In this way, the whole events of a scene and even a movie can be shown to the audience in a long view. By moving the camera, you can do something instead of the scene elements entering or leaving the frame, the camera moves them into the frame or out of the frame. The camera can follow a moving actor over a long distance.

\section{Types of camera movements}

The various camera movements can be divided into several categories.
First) camera movements on a fixed base such as: (pen, tilt).

Second) Transmitting movements of the camera by movement tools such as: (Traveling, crane, steady-camera and hand-held camera, etc.).

Third) the movements inside the camera lens (zoom in and zoom out).

In the following discussion, we will explain some of these camera movements.

\section{Move the pen on the camera}

The movement of the pen in the camera is the movement of the camera on a tripod and in terms of balance it is parallel to the ground. And its motion is along the horizon line. This is probably one of the most basic moves for a camera which is similar to turning a human head to the right or left while watching a ping pong game up close. Another subset of the Pan movement is the Pen Switch, which was common in decades ago and was used to change movie sequences. A switch pen is actually a very fast pen that moves from one fixed subject to another fixed subject. In order to be able to achieve this movement well, they use more telephoto lens to catch this type of pen.

\section{Tilt move}

The movement of the pen in the camera is a movement in which the camera is on a tripod and is parallel to the ground in terms of balance. And its motion is along the horizon line. This is probably one of the most basic moves for a camera which is similar to turning a human head to the right or left while watching a ping pong game up close. Another subset of pen movement is the pen switch it was common in previous decades and was used to change movie sequences. A switch pen is actually a very fast pen that moves from one fixed subject to another fixed subject. To be able to get this move well to get this type of pen, they mostly use telephoto lenses.

\section{Tilt move}

Tilt movement in a camcorder is called a movement the camera is placed on a tripod parallel to the surfaces and moves vertically and vertically. This movement is similar to the simple movement of a human head that lowers its head and raises it again and looks at the earth and the sky. When filming, the directors use a combination of these two movements to follow a chapter in one direction. This movement can be used to pay more attention to the greatness and power of the subject. For example, if the camera stops suddenly while moving, it will focus the viewer's attention on that location. If a telephoto lens is used to do this, the camera will move faster however, if a wide-angle lens is used to capture the motion of the tilt, the motion created in the image will be seen as smooth and soft. This type of movement and combining it with different lenses creates the director's desired feeling in the image, and as a result, the filmmaker's message is better conveyed to the audience. 


\section{Oblique motion}

This movement is a combination of pen and tilt movement. In such a movement, the camera revolves around a fixed axis, which in most cases is the same tripod. A left or right motion is smooth in the form of a curve from top to bottom or vice versa.

\section{Transitional motion}

The second part of the movements in the camera is the movements by the auxiliary movement tools and equipment.

\section{Trawling move in camera}

Traveling movement is another technical and complex movement of the camera with auxiliary tools in which the camera moves with him to follow the subject while moving. Sometimes the camera and the subject move in parallel and sometimes it moves at a 45 degree angle. Sometimes it moves away from or closer to the subject, for example from a long shot to a medium close-up view. Or vice versa, the movement of trawling is of two types, both forward and backward. To get the trawling motion, two strands of parallel rails, such as a train rail, must be placed on the ground and a camera and videographer on four wheels moving on rails it is placed and moved forward or backward or in the direction intended by the director with the subject. It should not be forgotten that the movement of the camera on the rails should be done very slowly and without vibration.

In some of the many properties that the director wants, fast trailing movements can also be used. Trawling is possible in some areas that are not in good economic condition which is not done as standard. Because having a complete travel requires a large budget. In these areas, instead of trawling, there are often items such as wheelchairs, vans, bicycles, cars and other moving items that can they use the sense of movement to convey to the audience. But in many cases, trawling with these devices does not provide good movement because the soft motion that Trawling can provide, those devices cannot And getting moving with this type of equipment will not be without movement shocks. The same shocks that occur in motion instead of conveying the feeling of motion completely to the audience in many cases, it conveys the opposite feeling.

\section{Crane movement}

Changing the height of the camera from top to bottom or from bottom to top is called moving the canvas which is done by a tool called a crane or pedestal stand in a TV studio. This movement is used to divert the audience's attention from one point to another or to divert the viewer's attention and go to other topics. This movement has been used many times in television programs to show the huge number of marchers in the streets. Cranes are widely used in historical and war films, and their use requires special coordination and skill. The view taken by the crane is the best way to move the camera to get away from the ground and introduce the space in which the story takes place. This camera movement can be used at the beginning or end of a sequence. The best example of this can be seen in Orson Welles' Citizen Kane. As the camera rises from the picture of Susan Alexander Kane on a rainy night, it shows the neon sign of the nightclub with her name engraved on it. In some cases you may need to combine these movements that is, the pan and tilt movement and the trawling movement of all three types of movement are combined.

\section{Steadicam}

A Steadicam is a tool for capturing images and eliminating unwanted movements which is used during shooting due to the movement of the cameraman. Vibration removal in the camera is done mechanically in this device and the movement of the camera separates it from the movement of the cameraman. Using a Steadicam, the cameraman can capture extremely smooth, shake-free images when moving fast, even on rough surfaces. There are many sizes and types of Steadicam. Depending on the type of camera used to capture the image and the environment from which it is shot, it can take many forms.

\section{Move the camera on the hand}

Moving the camera on the hand is one of the simplest camera movements. Using a handheld camera has its own method. Proper handling of these types of cameras is very important when filming. The cameraman holds the camera on his hand or shoulder or in front of his chest or abdomen and moves around the scene. This type of camera movement produces a kind of acceleration and tension throughout the film, which is more specific to documentaries. This gesture, if not used properly, can be annoying to the viewer who sees those flickering images. But if the camera is used on the hand in a scene that has tension and anxiety, it can be quite effective and convey that subject's anxiety well to the audience.

Camera movements in cinema cannot be without reason and logic. Because if you use the camera without reason and logic will not help you at all. In many cases, it may even damage the essence of your work. So remember that you should always follow the principles and criteria and reasons for moving the camera. There must be a logical reason for the camera to move in the scene Otherwise, the movement of the camera will be meaningless, and thus distracting you from presenting the purpose of the image you have in mind. When you want to use the camera movement in the scene, always try to move the subject first Then the camera starts moving slowly and at the end of the movement, first the camera stops moving and then the subject stops. I have already mentioned that there is a difference in moving the camera using a wide and telephoto lens. Be very careful in the type of use. The 
camera moves faster in the telephoto lens than in the wide-angle lens, so it moves smoothly when shooting with the telephoto lens. But when you want to use a trawling or dolly motion, you have to use a wide-angle lens to reduce camera shake. In many cases, a stabilizer is used to eliminate camera shake, but the vibrator takes away the real sense of motion from the image. Therefore, it should be tried to move the camera during shooting completely naturally so that you do not have to change it during editing.

The other part of shooting is framing, which can affect the movement of the camera and the feeling that movement creates in the audience. For example, when the camera is moving around the character, if the selected frame is a full shot, only the audience can see the space around the character and feel him in one place and space. But if in such a movement, a medium shot is used instead of the full shot frame, we will see less space from that place, but with this frame and the movement that rotates around the character, it can convey the state of dizziness to the audience. When the camera rotates around the character, the surrounding space also revolves around him, so it feels like everything is spinning around the character's head. So we must not forget that all the frames we choose for the image must be in line with the movements of our camera based on the feeling we want to convey to the audience. If this is not observed. It can make it difficult for us to convey the feeling of the scene to the audience, or it can even lead to failure. Mr. Sotoudeh has made this clear in an article on framing. In his article, he believes in the very importance of framing for image aesthetics. Sotoudeh believes that when we always want to create an image, in principle, we are choosing and he chooses when he chooses a visual filmmaker, he has essentially chosen a small part of the world in front of him to show to his audience. This is a smart choice from the world around the filmmaker to convey the message. The important thing here is that the world in front of the filmmaker's camera is fixed when the filmmaker takes it in his frame. In fact, he cut the part that he wants. This cut section alone has a message when a filmmaker adds camera movement to present it to the audience in the best possible way, he is essentially directly involved in creating the beauty and sending the message. Because the filmmaker tries to beautify and better present his goal and message to the audience with this choice and intervention.

Today, camera movements can be seen in all movies. Because since the advent of the camera in the world, filmmakers have been looking for a moving example. But in the past, camera movements were very rudimentary. Initially, the images were filmed outside the studio and then combined with the images inside the studio, which basically enabled the filmmakers to create beautiful effects. "Since the advent of cinema, technologists have been looking for practical ways "That will enable them to combine a scene from an actor in the studio with a background scene filmed elsewhere." Continuation of this work caused special effects in cinema. (Fielding, 238, 2008).
In many cases this was done well but the problem arose when the camera was moving. Because the camera movements did not match properly, the filmmaker had difficulty adjusting the images. Following all these discussions, the question arises as to why we seek beauty and its creation in cinema and society. What can beauty do for us that we would be in trouble without? If a film is not made with an aesthetic look, does the audience not understand that film? And does not receive the message? In answer to these questions, it can be said that aesthetics does not do much for humans It just gives him a different perspective. This view, created in the form of philosophy, interprets the film and provides it to the audience and helps them to understand the message of the film better, easier and deeper. Many scholars believe that philosophy exists in all branches and sub-branches of art. Therefore, philosophy cannot be separated from cinema and the art of illustration. "The relationship between film and philosophy in recent years has given rise to intense speculation. The fact is that today, film philosophy can be considered an independent field of research." (Tak, 37, 2017).

This is what makes film critics and theorists want it talking about cinema and its impact, they cannot deal with every single art in cinema Because each of them has its own philosophical interpretation, but when it is in the form of a cinematic image, it loses its original meaning. And it reaches a new meaning and in essence this meaning is specific to cinema. From this point of view, the philosophy of cinema should be studied completely independently. Because in other arts there is no such thing as movement, but cinema is a moving art and conveys its message to the audience by animating its characters. And it creates that movement by moving the camera in the scene. "Filming has a profound effect on the viewer's reaction to the film he sees on the big screen. Filming is effective in understanding the content of the film, "On the other hand, it powerfully shapes the reactions of the audience and the concepts that the viewer traces in the film." (Phillips, 65, 2010).

The filmmaker combines the movements of the camcorder with the movements of his characters so that he can convey his message to the audience. Sometimes these movements are combined so precisely that the audience does not feel the movements of the camera. This is how the filmmaker conveys his message to the audience in the best possible way. But if these movements are not well formed and the movements do not meet the correct criteria of camera movements and the movements inside the film can be felt, in which case the movement of the camera attracts the audience And this attraction of the audience to the movements of the camera makes it impossible for him to properly perceive the feeling and action of the scene. When the audience cannot receive the feeling and action of the scene, as a result, they cannot receive the message of the scene properly and in essence, it will distance the audience from the film, which results in the filmmaker failing to convey the message of the film to the audience. 


\section{Afghan Cinema}

With the arrival of cinema in Afghanistan, cinema enthusiasts used to make films with minimal equipment and facilities and in many cases, films are made outside of Afghanistan, such as "Love and Friendship", which is made outside of Afghanistan. In this film, we do not see complex camera movements. And most of the camera movements use pen movements. At that time, due to the lack of movement equipment such as cranes and trawling were not available to filmmakers, this type of movement is not seen in the film. But with the passage of time and the advancement of technology in the world, little by little these devices reached Afghanistan. In the films made in the 50's and 60 's, some of the camera movements with tools are seen in the films. One of the best films made during this period is "Men Promise" by Saeed Orikzay. Trawling and crane movements are not seen in this film. At the very beginning of the film, a tilt and pen movement is performed from the kites on the two characters sitting inside the room. The camera moves backwards. It could have been on a trawling, and it could have done a dolly-back move, which provides a nice, vibrating body movement, but the camera is on the hand instead of on the trawling. The camera slowly moves backwards and captures the two characters in the frame. In this part, due to the concerns of the character of the film, the movement on the hand has helped the tension inside the scene. But the same move would have been better and more attractive if taken on Traveling. Because the camera does not stop and continues to move, and the character "Shirjan" frames the film in close-up. This movement of the camera dolly is also on the hand. In most cases, dolly movement is used to penetrate a person's inner self in such cases, Dolly's movement should be very calm and without vibration so that the audience does not become anxious and can empathize with the character and receive his feeling from the scene. But in "Men Promise", this is not the case. The movement of the camera with a vibration caused by the movement of the camera on the hand causes vibrations in the shot, which can destroy the audience's sense.

In films made after the Taliban rule in Afghanistan, filmmakers have been able to make more use of cinematic tools. Given that many filmmakers in Afghanistan have learned cinema experimentally, some of them do not understand the concepts of camera movements in cinema, only using the movements on their own instinct and instinct. In many cases, we see movements in the films that did not need to be used at all, but were used in a part of the film without any reason or logic. Some filmmakers with film education also entered the film industry in Afghanistan in the post-Taliban era. Siddiq Barmak's film "Osama" can be considered one of the achievements after the Taliban rule in Afghanistan. Siddiq Barmak, who has a film education, is well acquainted with the language of cinema and camera movements and its meaning and concept in cinema. But it should not be forgotten that at the beginning of "Men Promise" the scene has a calmness inside it, only the character is a little worried if there is a lot of tension in "Osama". In this film, the movement of the camera on the hand used by Siddiq Barmak is quite appropriate, because the vibrations caused by the camera in the film indicate an accident. In such cases, the filmmaker must use camera movements that can add to the tension that is in the scene, which is well seen in Osama's film and the director has been able to do well. Use the movement of the camera on the hand to convey a sense of fear to the audience. But when we go inside the hospital, there is no more vibration of the camera. The movements are quite calm because there is no more war and anxiety inside the hospital. The camera moves slowly. In many shots, the camera moves so slowly that in many cases the audience does not feel the movement at all. Also, in the scene where the doctor goes to see the sick old man, the movement of the camera is extremely smooth and without vibration. In another part of the same film, in the scene where the girl is asleep and her hair is cut short, the camera slowly moves from her legs to her face without moving. Here, Siddique Barmak has used very precise movement tools in his film. And it instills a sense of calm after the storm to its audience with this camera movement.

Sahraa Karimi is another Afghan filmmaker who made films after the Taliban rule in Afghanistan. Sahraa Karimi proved that young Afghans can align with world cinema and produce films like them by making "Eve, Mary, Aisha", a social drama film. In many of the films produced by experimental filmmakers in Afghanistan, we see camera movements, but in many of them, the movements are completely in place for no reason. Or in many movies we see that the position of the camera in the scene changes and the hypothetical line is broken. This can be done the director did not know about the existence of a hypothetical line and the correct use of camera movements. But people like Sahraa Karimi make good use of these camera movements in their film and try to make the best use of it to attract and convey the meaning of the film to the audience. When the director wants to make a move in a scene. The first thing that bothers him. Move characters and move the camera. In these movements, it is very important to maintain continuity. "Keeping the camera steady on one side is a limiting factor. You often want to go the other way because you will have a more dynamic composition and a better angle of view on that side. For this purpose, you can do this by cutting it out and to neutralize the movement and insert the actor to determine this change, or with the help of opposite movements in a part of the screen." (Arichen, 214,215, 1996).

These shifts can be seen a lot in the movie "Eve, Mary, Haisha". But what Sahraa Karimi has done in order to be able to maintain the continuity of her scenes in the scenes Karimi uses hand-held camera movements Karimi uses hand-held camera movements In the first step, she frees herself from the shackles of the hypothetical line in the scene, and in the second step, with the vibrations that she has created in the camera. She was able to convey to the audience the 
unrest that exists within the characters. This work by Sahraa Karimi and the use of camera movement on the hand has given the film a documentary look that helps the audience to accept the reality of the story. And it gives the audience the feeling that they are watching a documentary, so the audience feels empathy with the characters.

\section{Result}

Cinema is a dynamic and moving art that fascinates the audience with its movement. If we cannot use the camera and scene movements properly in the film, we have not helped to establish the connection between the film and the audience. "If the director wants to go from scene to scene without using cuts (to draw an all-encompassing unity), His camera has to move from scene to scene."It is the creation of these movements that makes art seem natural." (Mitri, 285, 2015).

These gestures are not used properly in many films by Afghan filmmakers As a result, they fail to communicate with their audience. This failure to communicate caused the film to fail in the market, and as a result, the filmmaker could not continue filmmaking in the cinema. This is why there are so few filmmakers in Afghanistan today who produce films. Because many of them who have studied cinema experimentally do not have much information about the movements and the effect of those camera movements on the audience. Recently, educated directors who have entered the world of Afghan cinema are trying to produce films that meet the principles and academic standards of world cinema. They try to convey the best camera and character movements in the scene and by combining those movements with the mezzanine in order to convey their message to their audience in the best possible way.

\section{Resources:}

Sotoudeh, Sajjad. Sotoudeh, Milad. Alsti, Ahmad Yousefian, Mohammad Jafar. (2016), The Aesthetics of Framing and De-framing in Iranian Cinema in the 1980s, Journal of Fine Arts, Volume 21, Number 2, Tehran

Fielding, Raymond. (2008), Special Effects Filming Technique, translated by Ahmadi Alri, Hamid. Tehran, Soroush.

Vine, wolf. Carl, Howie. (2017), Philosophy of Cinema, translated by Parsa, Mehrdad. Tehran.

Phillips, William. (2010), Fundamentals of Cinema, Second Edition. Translation: Qasemian, Rahim. Tehran, Saqi Publishing.

Arikhen, Daniel. (1996), How to direct? Translation: Akbari, Abbas, Tehran, Center for the Development of Documentary and Experimental Cinema.

Mitri, Jean. (2015), Psychology and Aesthetics of Cinema. Translation: Azimi, Shapoor, second edition, Tehran, Sepehr.

\section{Filmography:}

Vertigo. (1958). Directed by Alfred Hitchcock, USA.

Birdman. (2014). Directed by Alejandro Gonzalez Inarritu, USA.
Citizen Kane. (1941). Directed by Orson Welles, USA. love and friendship. (1945). Directed by Rashid Latifi, Afghanistan.

Men promise. Directed by Saeed Orikzay, Afghanistan. Osama. (2003). Directed by Siddiq Barmak, Afghanistan. Eve, Mary, Aisha (2019). Directed by Sahraa Karimi, Afghanistan. 